\title{
A case study on the effect of soil compaction on potato growth in a loamy sand soil. 1. Physical measurements and rooting patterns
}

\author{
F. R. Boone ${ }^{1}$, J. Bouma 2 and L. A. H. de Smet ${ }^{2}$ \\ 1 Tillage Laboratory, Agricultural University, Diedenweg 20, Wageningen, \\ the Netherlands \\ 2 Soil Survey Institute, P.O. Box 98, Wageningen, the Netherlands \\ Accepted: 8 February 1978
}

Key words: soil compaction, potato, tillage, soil physics, pedology, rooting

\section{Summary}

An interdisciplinary field study, including consideration of soil tillage, soil physics, pedology and crop science was made to study the effect of soil compaction on potato growth in a young, alluvial loamy sand soil in the very dry growing season of 1976. The treatments consisted of different degrees of compaction in or just below the arable layer also considering the effect of irrigation. Physical measurements and rooting patterns are discussed in this paper. Potato growth will be analysed in a companion paper.

Compaction decreased pore volume whereas the volumetric water content at any given pressure potential was increased or decreased depending on the degree of compaction. A high mechanical resistance encoutered by the roots proved to be the primary factor affecting root elongation. Roots penetrated the compacted layers in all treatments but at very different rates. As a result the pressure potential at the rooting front was relatively low as long as roots were growing in the compacted layers. Moisture flow to the roots by capillary rise from the watertable occurred during the entire growing season but varied significantly among treatments as a function of the distance above the water-table and hydraulic conductivity of the various layers. Moderate compaction increased, but severe compaction decreased the potential for capillary rise in the topsoil. The ploughpan in the subsoil increased the potential for capillary rise. Critical groundwater levels at a given rooting depth were calculated for different steady upward fluxes for some of the treatments.

\section{Introduction}

Agricultural mechanization increasingly involves use of heavy machinery which compacts or puddles the soil under adverse moisture conditions, thereby changing 
its physical properties. These changes may significantly affect rooting conditions for a crop, and thereby its potention for growth, by reducing soil aeration and by increasing soil mechanical resistance. Of course, soil structure can be improved by soil tillage. Soil structural conditions during the growing season are therefore a result from both loosening and compaction. The question, then, arises as to which conditions are optimal and how they can be achieved.

A comprehensive interdisciplinary study, including consideration of soil tillage, soil physics, pedology and crop science appears suited to provide relevant data needed to answer the question raised. Such data are not well available, which is probably due to the high cost of these types of studies. The interdisciplinary approach was followed in field experiments during several years from which results of 1973 are reported elsewhere (Boone, et. al., 1975). The results discussed below are covering the very dry 1976 growing season.

Potatoes were chosen because yields of this crop had been consistently different in various parts of the country and differences were thought to be due to soil structural features. Like other root crops, potatoes are sensitive to soil structure especially with regard to quality as was shown in field experiment with different tillage systems including zero-tillage (Bakermans et. al., 1974).

Aside from testing the effect of structural conditions on plant growth, the study was also intended to broadly test the potential for irrigation in relation to soil structure. Irrigation is increasingly being applied by farmers in the Netherlands, even though few detailed data about optimal application rates are available

Recently, many computer simulation programs have been developed for crop growth (e.g. Feddes et al., 1978). Verification of results from these programs is often not well possible due to lack of comprehensive field data, which should not only include detailed climatic and soil physical data, but also data on root distribution and plant growth. Data gathered were selected to be complete enough that applications of simulation should be possible. The soil moisture regime and the associated aeration and mechanical resistance of the soil were used as important diagnostic tools as well as the rooting pattern. This paper will report on the results of the physical and the rooting studies. Potato production will be discussed in a separate paper (van Loon \& Bouma, 1978).

\section{Materials and methods}

The soil

The studies were made in a calcareous soil near Lelystad, the Netherlands, on the Research Station for Arable Farming and Field Production of Vegetables. The soil could be classified as a Nesvaaggrond (de Bakker \& Schelling, 1966) or a Cumulic Fluvaquent, coarse loamy, mixed, mesic (Soil Survey Staff, 1975). This alluvial soil was reclaimed in 1957. Tile drains were at a depth of $1.10 \mathrm{~m}$ below surface, but never conducted water during the period of study, due to deep watertables in the dry year 1976.

The soil profile can be described as follows (the depth notation is in terms of the vertical distance below the top of the potato ridges, and horizon designations 
are according to de Bakker \& Schelling, 1966).

Ap 1: $(0-20 \mathrm{~cm})$ Sandy loam $(10 \%$ clay; $35 \%$ silt; $2.3 \%$ organic matter and $\left.7 \% \mathrm{CaCO}_{3}\right)$.

Ap 2: $(20-40 \mathrm{~cm})$ as Ap 1 but occurring below the potato ridge.

C21g: $(40-50 \mathrm{~cm})$ Loamy fine sand $(5 \%$ clay; $15 \%$ silt; $0.9 \%$ organic matter; $3 \% \mathrm{CaCO}_{3}$ ); clay content varying due to the occurrence of remnants of the old sedimentary structure which was disturbed by deep tillage in 1970 to a depth of $70 \mathrm{~cm}$. Contains many shells.

C22g: $(50-70 \mathrm{~cm})$ As C21 g but locally with fragments containing some more clay (loam texture).

C23g: (70-90 cm) Moderately stratified soil composed of thin layers with sandy loam, loam and sand texture; half ripened and perforated with root channels.

C24g: (deeper than $90 \mathrm{~cm}$ ) as $23 \mathrm{~g}$ but unripened.

\section{Treatments}

After harvesting onions and applying $210 \mathrm{~kg} / \mathrm{ha} \mathrm{P}_{2} \mathrm{O}_{5}$ and $210 \mathrm{~kg} / \mathrm{ha} \mathrm{K}_{2} \mathrm{O}$ the soil was ploughed to a depth of $20 \mathrm{~cm}$. The different soil compactions were realized in the autumn of 1975 (treatment P) or before potato planting on 15 April 1976. All field operations after compaction were performed with a tractor with a tread width of $210 \mathrm{~cm}$. Since row distance was $75 \mathrm{~cm}$ the soil beneath two rows out of four was not influenced by wheels. All samplings were made in these rows. The treatments were designated as follows:

$\mathrm{L}=$ loose, not compacted (reference);

$\mathrm{LI}=$ loose irrigated, as $\mathrm{L}$ but with moisture added through surface irrigation; $\mathrm{CM}=$ compacted moderately. Achieved by driving once over the entire soil area with a heavy tractor (weight $5600 \mathrm{~kg}$, inflation pressure 1.5 at). The topsoil was a few procent below field capacity (defined as a pressure potential of $-100 \mathrm{~cm}$ water $(\mathrm{pF} 2.0))^{\star}$;

$\mathrm{CMI}=$ compacted moderately irrigated, as $\mathrm{CM}$ but with surface irrigation;

$\mathrm{CS}=$ compacted strongly, as $\mathrm{CM}$ but driving repeated four times;

$\mathrm{P}=$ ploughpan, strongly compacted subsoil below Ap. Achieved by removal of the Ap and repeated driving over the exposed subsoil with a heavy tractor and a loaded wagon, after which the topsoil was redeposited.

Except treatment L, which was in triplicate, there were no replicates and each treatment was applied to an area of $350 \mathrm{~m}^{2}$. Prior to planting, a plant-bed of about $10 \mathrm{~cm}$ was made on 14 April with a powered harrow. This means that part of the compacted arable layer was loosened again.

On 28 April final ridges were made and $205 \mathrm{~kg} \mathrm{~N} / \mathrm{ha}$ in the form of $\mathrm{Ca}\left(\mathrm{NO}_{3}\right)_{2}$ was given. Irrigation water was added to treatments CMI and LI in the period of 10 June to 24 July (see Fig. 1 for quantities and times of application) through perforated, flexible pipe, between the potato ridges. Infiltration of water was very rapid initially but rates decreased later due to soil crusting.

* $1 \mathrm{~atm}=98066.5 \mathrm{~Pa}$ and a pressure of $1 \mathrm{~cm}$ water $=98.0665 \mathrm{~Pa}$ in the SI system. 


\section{Physical methods}

Water-table depths were measured in each plot in 3-m deep perforated pipes. Moisture retention curves and bulk densities were determined by applying standard techniques to at least ten $100 \mathrm{~cm}^{3}$ cores obtained in situ from the major compacted and uncompacted layers. Weekly measurements were made of soil moisture contents in all the treatments by augering at different locations at $10 \mathrm{~cm}$ depth intervals, and by determining gravimetric moisture contents of a composite mixed sample. These values were 'translated' into pressure potentials by means of the proper retention curve. This procedure was expected to yield representative results in these rather heterogeneous soils. Direct tensiometric measurements of pressure potentials would have been very laborious because many measurements would be needed due to the small effective radius around each tensiometer cup. Besides, such measurements would have been restricted to pressure potentials above $-800 \mathrm{~cm}$, which would not have been adequate.

Hydraulic conductivities at saturation $\left(\mathrm{K}_{\mathrm{sat}}\right)$ were determined in situ with the crust test (e.g. Bouma, 1977). The procedure implies carving out a cylinder of soil (30 cm diameter, $30 \mathrm{~cm}$ high), encasing it in gypsum, followed by measurement of the steady infiltration rate under shallow ponded conditions. Conductivities of unsaturated soil were determined in triplicate for each layer by the method of Arya et al. (1975), which yields diffusivity values that can be transformed into $\mathrm{K}$ values by moisture retention data.

Oxygen concentrations of soil air were determined polarographically every week during the first growth of the crop as long as soil water content was high enough so as to expect a marked response.

Diffusion chambers were placed at a depth of $35 \mathrm{~cm}$ at the transition from Ap2 to $\mathrm{C} 21 \mathrm{~g}$ and in the $\mathrm{C} 22 \mathrm{~g}$ horizon at a depth of $60 \mathrm{~cm}$.

The Oxygen Diffusion Rate (ODR) was measured in the same period with a slightly modified method of Letey \& Stolzy (1964). The ODR was also measured in the laboratory within undisturbed soil cores brought at a certain suction.

Cone resistances were measured in the field with a registrating penetrometer (van Soesbergen \& Vos, 1972) at the start of the experiment (cone-base $1 \mathrm{~cm}^{2}$, $60^{\circ}$ angle). In the laboratory cone resistances (cone diameter $2 \mathrm{~mm}, 90^{\circ}$ angle) were measured in cores with soil aggregates $(<10 \mathrm{~mm}$ diameter) compacted to different pore volumes at pF 2 and brought thereafter at different water contents.

\section{Root observations}

Rooting patterns were observed according to a slightly modified method of Reymerink (1964) at least 4 times during the growing season (Boone et al., 1975). In a shallow trench perpendicular to the potato ridge a smooth vertical wall was prepared directly below the potato plant onto which the boundaries of the different soil layers were delineated. These lines were transferred to a transparant plastic sheet. Roots were made visible by using a small knife removing surrounding soil for a thickness of a few millimeters. A drawing of all observed roots was then made on the plastic sheet. Afterwards counts of the number of roots at every depth or horizon were made on photographic reproductions. 

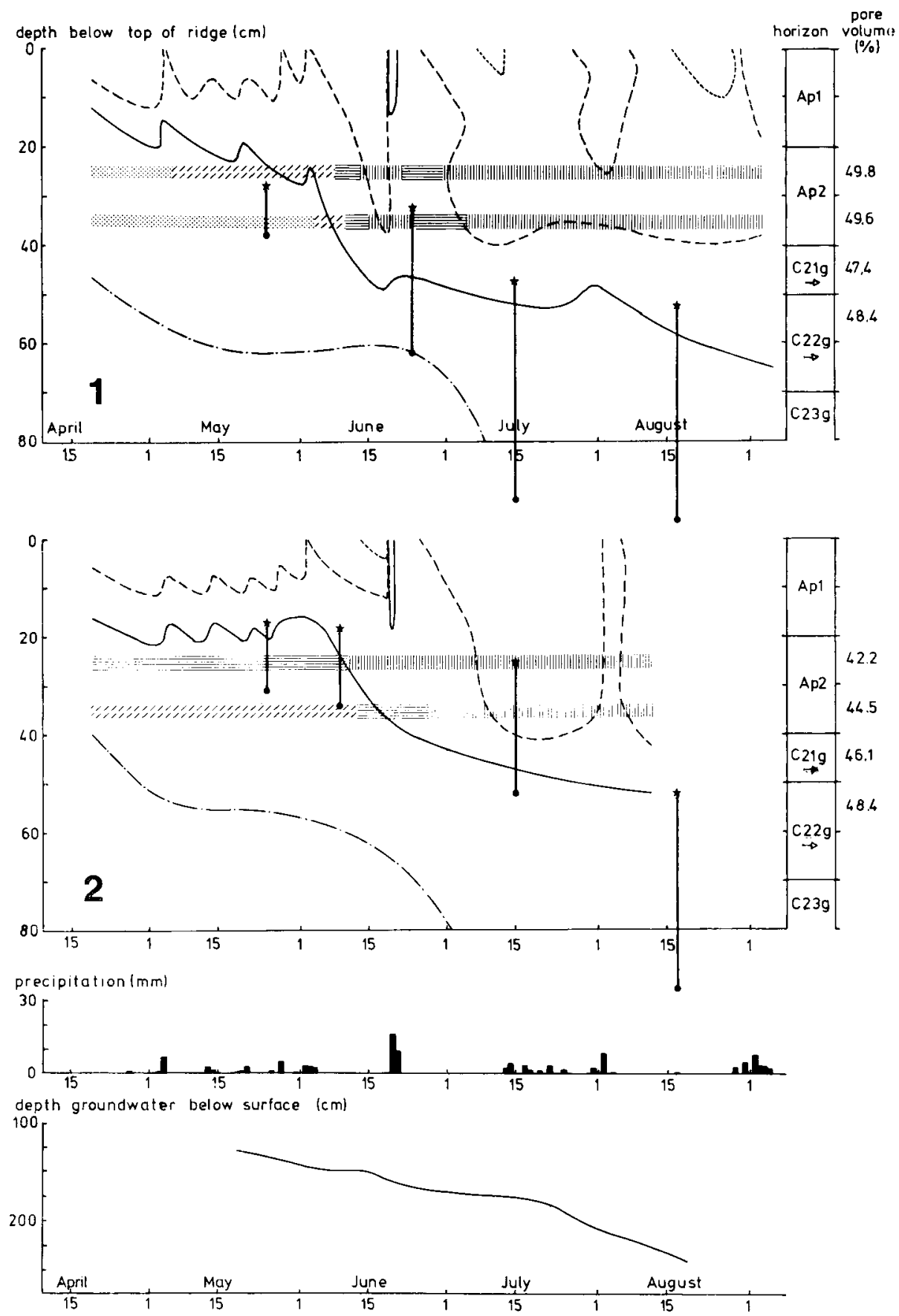


\section{Results and discussion}

Horizon designations, pore volumes and precipitation patterns are reported in Fig. 1 - 3, as well as the groundwater levels, the derived pressure potentials of the soil water and the cone resistance at different depths during the growing season. Depth of rooting at different dates was indicated as a range, noting depths at which $80 \%$ and $100 \%$ of the roots were observed. Results will be presented and discussed in the following points.
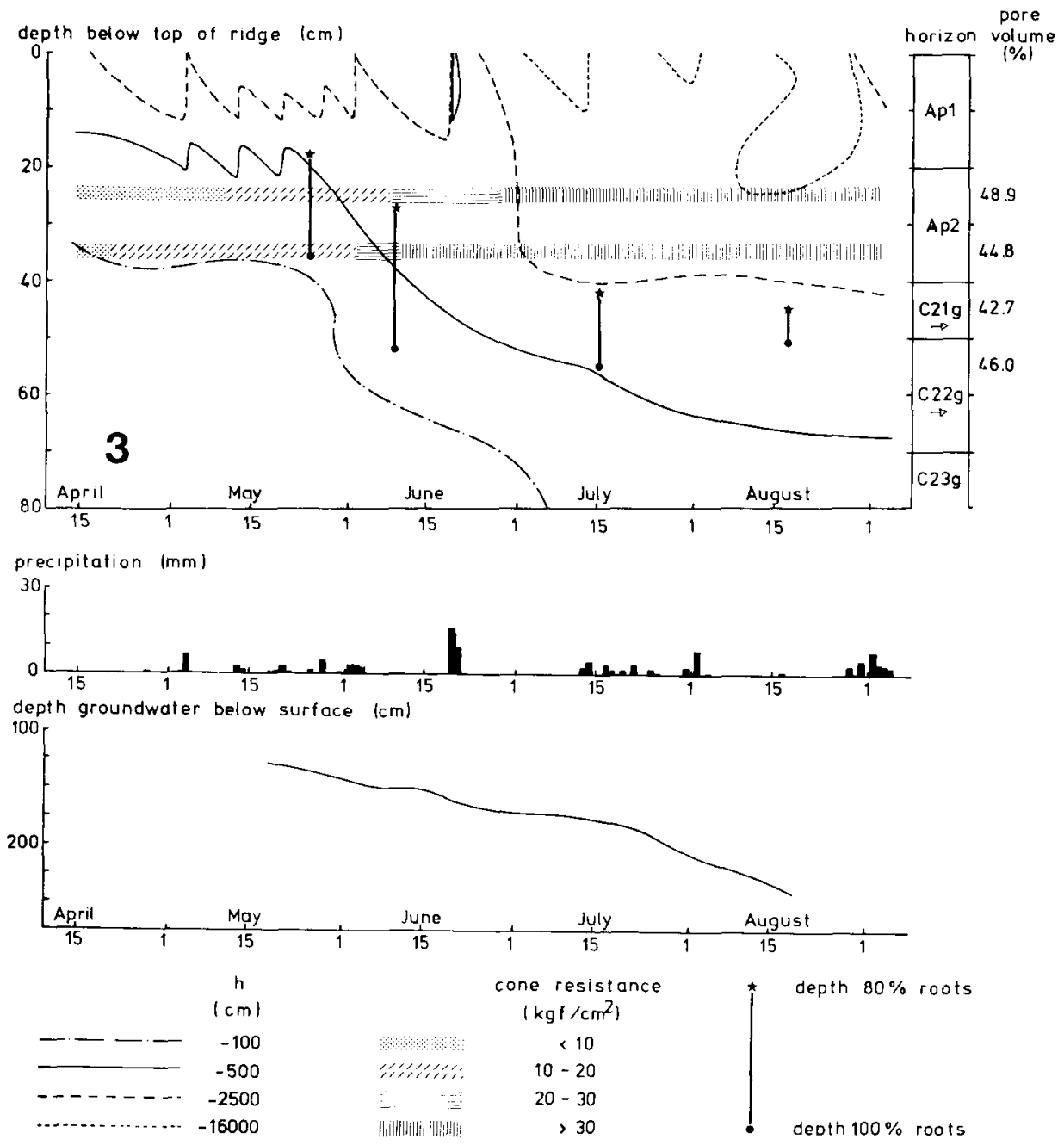

Fig 1 - 3. Horizon designations, pore volumes, precipitation patterns, groundwater levels, derived pressure potentials (h), rooting depths and cone resistances at different depths during the growing season for treatments L (Fig. 1, opposite page), CS (Fig. 2, opposite page) and P (Fig. 3.) 
Compaction decreased pore volume whereas the volumetric water content was increased or decreased

Pore volume of the Ap2 was high in treatment L (Fig. 1). Driving once over the topsoil reduced pore volume drastically in the Ap2 especially directly below the potato ridge (treatment CM). A further, but much smaller decrease occurred when driving over the topsoil was done four times (treatment CS, Fig. 2). Ridging operations did therefore not result in loosening of the most compacted part of the Ap2, which generally does not occur immediately below the traffic surface but slightly deeper (see van Ouwerkerk \& Boone, 1970). Compaction of the topsoil resulted in slightly lower porosities of the $\mathrm{C} 21 \mathrm{~g}$ as compared with treatment L (Fig. 1 and 2) but lowest porosities for the $\mathrm{C} 21 \mathrm{~g}$ were obtained in the ploughpan in treatment $\mathrm{P}$ (Fig. 3). In general, porosity values for the $\mathrm{C}$ horizons varied widely due to the heterogenity of the soil resulting from deep tillage.

At saturation and at high pressure potentials $(\mathrm{h}=-10$ and $-30 \mathrm{~cm})$ the higher the pore volume in the Ap the higher the volumetric soil water content (illustrated for $\mathrm{h}=-10 \mathrm{~cm}$ in Fig. 4.) At $\mathrm{h}=-100 \mathrm{~cm}$ and at lower potentials treatment $\mathrm{L}$ had a lower water content than treatment CS, whereas treatment CM had the highest water content. This can be explained in the following way. Because compaction increases the number of finer pores in a certain volume, moisture content at every pressure potential will increase upon compaction up to saturation

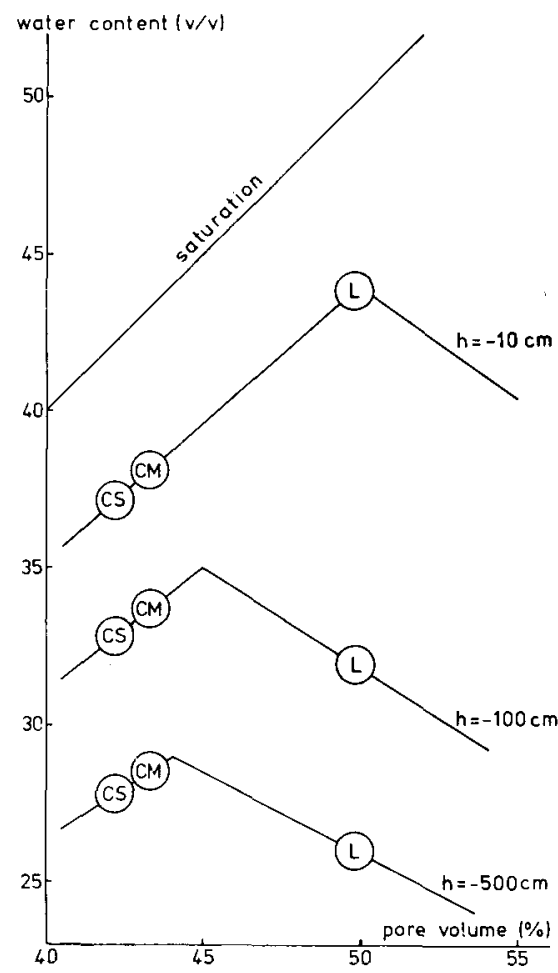

Fig. 4. Relationships between pore volume and water content at different pressure potentials (h) for treatments $L, C M$ and $C S$. 


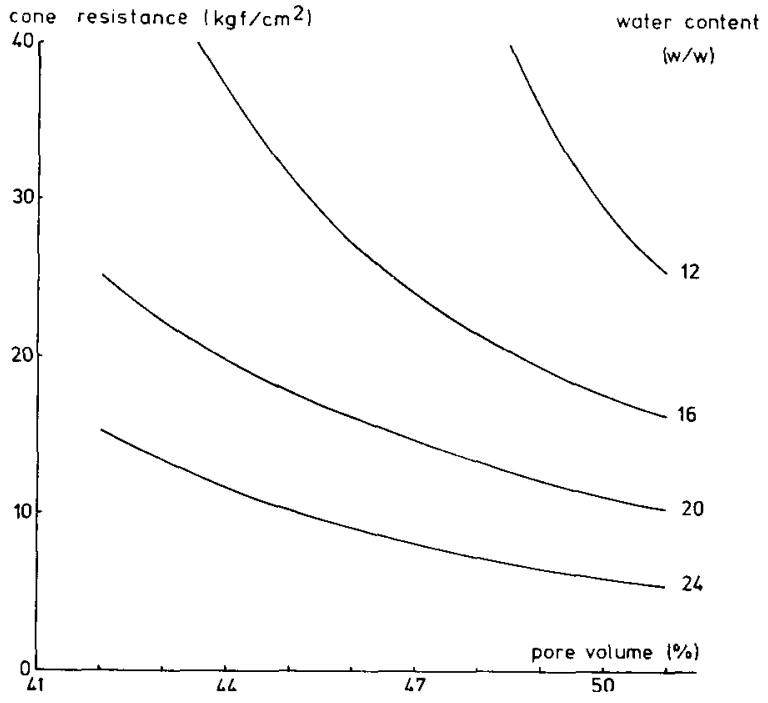

Fig. 5. Relationships between pore volume and cone resistances as a function of different water contents.

and will decrease upon further compaction by loss of water. If saturation occurs within the pore volume range encountered in the field, optimum curves are to be expected (Kuipers, 1968). They are therefore most likely at high pressure potentials as was already observed by von Nitzsch (1937). However, a decrease in soil water content upon compaction occurs already here far before saturation is obtained. As a result optimum curves are found even at the lower pressure potentials examined.

Compaction and a subsequent strong decrease in watercontent during the growing season increased cone resistance to high levels

Already at planting there are significant differences in cone resistance of the arable layer. Treatment $L$ had a cone resistance of less than $10 \mathrm{kgf} / \mathrm{cm}^{2 \star}$. The most compacted parts of the Ap2 of treatment $\mathrm{CM}$ and $\mathrm{CS}$ had cone resistances of 15 to 20 and more than $25 \mathrm{kgf} / \mathrm{cm}^{2}$, respectively.

Although the mean pore volume was not as low as the corresponding value for the strongly compacted arable layer, cone resistance of the original ploughpan was rather high at some places $\left(20\right.$ to $\left.30 \mathrm{kgf} / \mathrm{cm}^{2}\right)$. The strongly compacted ploughpan of treatment $P$ was much thicker $(15 \mathrm{~cm}$ instead of $5 \mathrm{~cm}$ ) and had a cone resistance between $25 \mathrm{kgf} / \mathrm{cm}^{2}$ in the upper part increasing to $35 \mathrm{kgf} / \mathrm{cm}^{2}$ in the lower part. Below the ploughpan cone resistance gradually decreased to $15 \mathrm{kgf} / \mathrm{cm}^{2}$.

Soil water content decreases because of evaporation, and so cone resistance increases (Fig. 5). This is the more so as the soil becomes more dense. Cone resistances of the treatment diverged therefore increasingly during the growing season. Cone resistance provides only an index of resistance and is not a measure

* $1 \mathrm{kgf} / \mathrm{cm}^{2}=98066.5 \mathrm{~Pa}$ in the SI system. 
of the forces encountered by growing roots. Roots penetrate soil more easily than penetrometer probes by following paths offering less than average resistance (e.g. Barley, 1976). Nevertheless the vertical penetration and proliferation of the root system is impeded as the mechanical resistance increases.

In the dry growing season compaction affected aeration only to a minor degree Compaction decreased gas diffusion and had a distinguished effect on oxygen concentration. The denser the soil, the lower the oxygen concentration at a certain depth. However, during the entire growing season no low concentrations were measured at rooting depth. The lowest concentrations were measured in treatment $\mathrm{CS}$ at the moment that a few roots had penetrated some disance into the $\mathrm{Ap}_{2}$, but $5 \mathrm{~cm}$ deeper than the deepest root, oxygen concentration was still $15 \%$.

The ODR measured in the field was high and only slightly influenced by the different treatments. This was in line with the determinations in undisturbed cores. From these observations of oxygen concentrations and soil water content it was concluded that there have been no aeration problems on the non-irrigated treatments and only during a short period on treatment CMI (15 July).

Roots penetrated the compacted layers in all treatments but at very different rates Depth of root penetration can be considered in terms of 'effective' depth, for which the occurrence of $80 \%$ of roots has been used (Rijtema, 1971) or in terms of the depth of maximum penetration (Fig. 6a and b). Either way, roots penetrated most rapidly in treatment L. Considering $80 \%$ of all roots, treatment CM is closer to treatment $\mathbf{L}$ than to treatment $\mathrm{CS}$ which had very superficial rooting during a long time. The first roots of treatment $\mathrm{CM}$ and CS reached the $\mathrm{C} 21 \mathrm{~g}$ 2 and 4 weeks later, respectively, than treatment $\mathrm{L}$. With $80 \%$ of the roots the differences were even more pronounced.

The rate of root growth below the C21g was very fast (about $2 \mathrm{~cm} /$ day) and, except for treatment $P$, nearly equal for all treatments (Fig. 6a). In the first part of July roots of treatment CS were at a depth of $40 \mathrm{~cm}$ whereas roots of treatment $\mathrm{L}$ were more than twice as deep. Maximum rooting depths, however, were only slightly different except for treatment $\mathrm{P}$, where roots hardly penetrated the compacted subsoil.

Irrigation slowed downward root penetration significantly. Whereas maximum rooting depth was not influenced as much, the $80 \%$ level was significant shallower than on treatment $P$. There was no interaction observed between compaction and irrigation when considering maximum rooting depth, but interaction was observed at the $80 \%$ level. The more superficial rooting of treatment CMI became obvious already on 24 June soon after the start of the irrigation on 10 June. So aeration problems which occurred around 15 July cannot be the reason for the superficial rooting. Apparently there was no need for deeper rooting because adequate water was available in the rooted soil layers.

Compaction and irrigation changed root density (expressend here as number per $\mathrm{cm}^{2}$ counted on a profile wall) markedly.

Only in the potato ridges $\left(\mathrm{Ap}_{1}\right)$ there were no systematic differences among treat- 


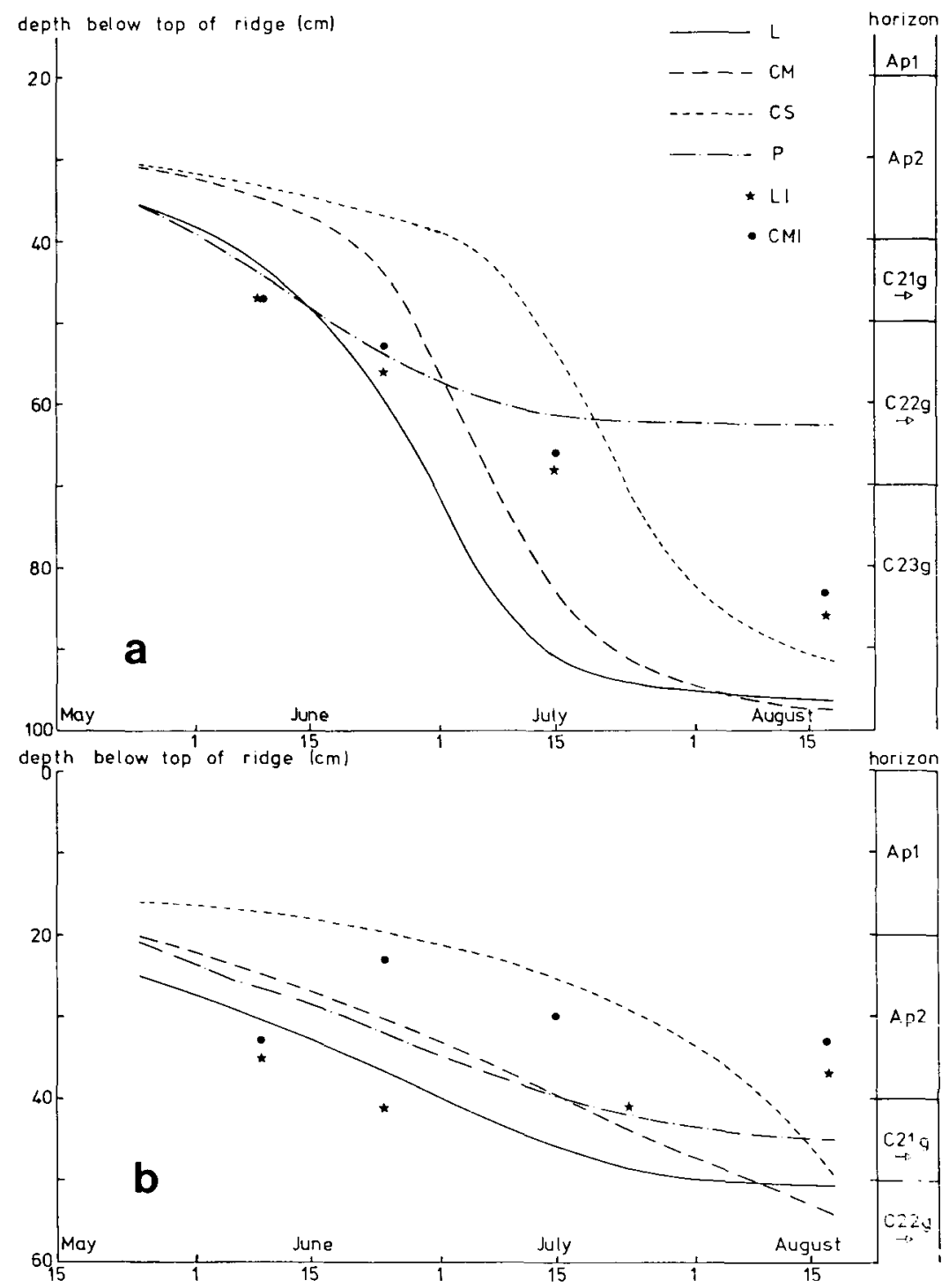

Fig. 6. Rooting depths as a function of time for different treatments. Fig. 6a represents the $100 \%$ root level and Fig. $6 \mathrm{~b}$ the $80 \%$ level.

ments. Treatment $\mathrm{L}$ contained on $15 \mathrm{June}$ in the first $10 \mathrm{~cm}$ below the ridge roughly 2 times as many roots as treatment $\mathrm{CM}$ and 6 times that of CS (Fig. 7a and b). Both rates were 2 in the middle of August. Root density was $>0.3$ in the first $10 \mathrm{~cm}$ below the ridge already at the beginning of June in treatment $\mathrm{L}$, whereas the same density was not reached until the last week of July for treatment CS. 
In the $\mathrm{Ap}_{2}$ lower densities in the compacted treatments were found because roots reached a certain depth later whereas also root proliferation was hampered by a high mechanical resistance. On the contrary, differences in the $\mathrm{C}$ horizon can be explained solely by a later start of root growth. The first part of the ploughpan of treatment $\mathrm{P}(40-45 \mathrm{~cm})$ had as many roots as treatment $\mathrm{L}$, but much more roots than treatments CM and CS.

Pressure potentials at the rooting front were low as long as roots were growing in the compacted layers

There was little precipitation (Fig. 1) in the entire summer period, which is not a normal situation for the Netherlands ( $1 \%$ year). Conditions in wetter growing seasons would be quite different.

One week after emergence of the potatoes (observations on 24 and 25 May) the pressure potential at the rooting front $(80 \%$ level) was near $-500 \mathrm{~cm}$. After
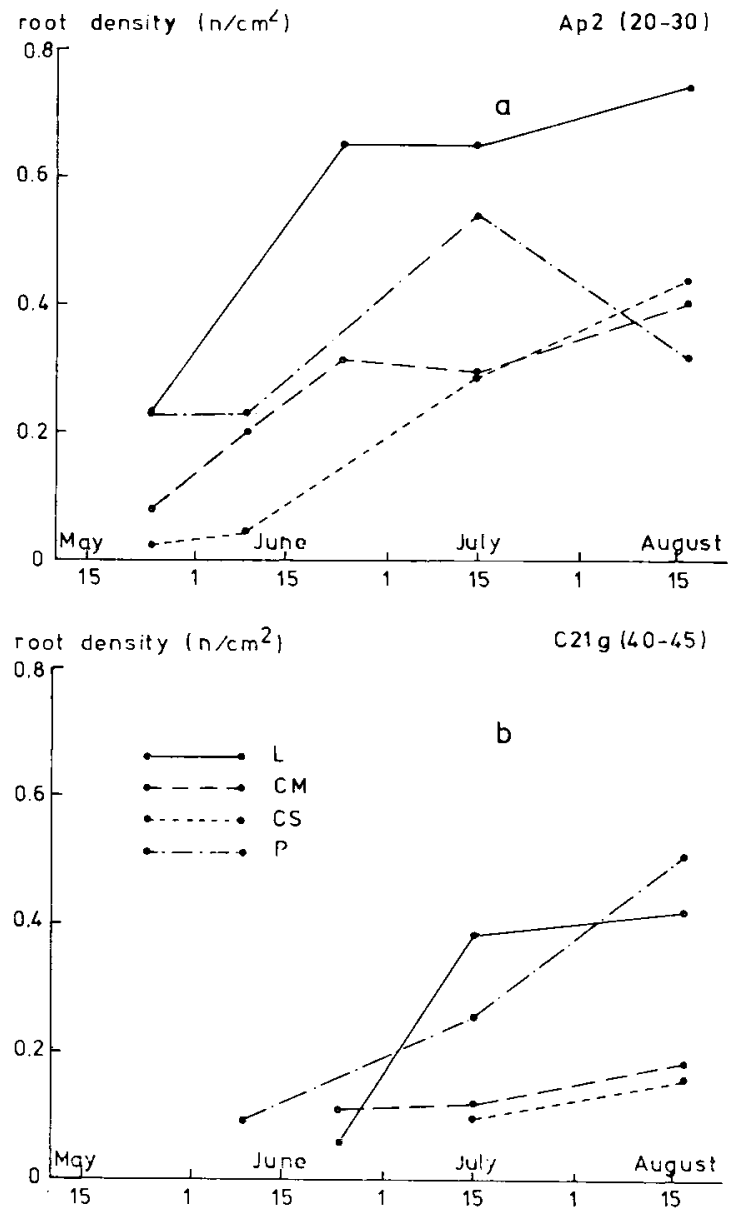

Neth. J. agric. Sci. 26 (1978)
Fig. 7. Root densities as a function of time in two soil horizons. 
that time the potential decreased below that level indicating that the extraction rate exceeded the rate by which more readily available moisure in deeper soil layers became available to elongating roots. Potentials at the rooting front decreased most strongly in the compacted treatments where vertical root elongation had been retarded. For exemple, potentials corresponding with $-2500 \mathrm{~cm}$ were reached on 15 July in treatments CM (not shown) and $\mathbf{P}$ (Fig. 3), whereas this value was clearly exceeded in treatments CS (Fig. 2). Even though a higher value was measured on $15 \mathrm{June}$, the potential was still near $-500 \mathrm{~cm}$ in treatment L (Fig. 1) on 15 July.

Once the roots passed the compacted $\mathrm{Ap}_{2}$ they penetrated with a higher growth rate into the subsoil. This resulted in moisture potentials again near $-500 \mathrm{~cm}$ at the rooting front in the middle of August in all treatments, except for treatment $P$, where potentials were still near $-2500 \mathrm{~cm}$.

Subsoil compaction apparently inhibited vertical root elongation, forcing roots to more completely deplete the moisture present in the rooted volume of soil. But the general assumption that a pressure potential of $-16000 \mathrm{~cm}$ is reached at the lower boundary of the 'effective' root zone at the end of the growing season is not correct for this study.

Moisture flow to the roots by capillary rise from the water-table occurred during the entire growing season, but varied among treatments

The hydraulic conductivity at saturation $\left(\mathrm{K}_{\mathrm{sat}}\right)$ of the $\mathrm{Ap}_{2}$ decreased by compaction from $120 \mathrm{~cm} /$ day (treatment $\mathrm{L}$ ) to $12 \mathrm{~cm} /$ day (treatment $\mathrm{CM}$ ) and $8 \mathrm{~cm} /$ day (treatment $\mathrm{CS}$ ). The $\mathrm{K}_{\mathrm{sat}}$ of the subsoil, measured from $42-67 \mathrm{~cm}$, decreased from $80 \mathrm{~cm} /$ day (treatment L) to $16 \mathrm{~cm} /$ day (treatment $\mathrm{P}$ ). The decrease must be attributed to the disappearance of larger voids, which has a very pronounced affect on the magnitude of $\mathrm{K}_{\text {sat }}$ (Bouma \& Anderson, 1973). However, $K_{\mathrm{sat}}$ is hardly of significance for determining capillary rise, which is most relevant for this study.

Formation of a more compact soil with finer pores results in flattening of the moisture retention curve and the $\mathrm{K}$-h curve yielding relatively higher values for moisture contents and $\mathbf{K}_{\text {unsat }}$ values, respectively, at comparable pressure potentials. This allows a higher capillary rise at a given pressure difference as can be estimated by a graphical integration procedure with measured $\mathrm{K}$ curves for one or several layers (e.g. Bouma, 1977). Theoretical heights (z) of capillary rise were calculated with the graphical procedure for three steady upwards fluxes, illustrating the effects of topsoil and subsoil compaction (Fig. 8a and b). For example, a steady flux of $1 \mathrm{~mm}$ /day could be maintained in the topsoil of treatment CM for a distance of $145 \mathrm{~cm}$ with steady boundary potentials of zero and $-1000 \mathrm{~cm}$. However, the comparable distance was only $35 \mathrm{~cm}$ in the uncompacted topsoil and $100 \mathrm{~cm}$ for treatment CS. Apparently, compaction can be so strong so as to decrease the potential for capillary rise. Corresponding differences between treatments $\mathrm{CM}$ and $\mathrm{CS}$ were also described for moisture retention data.

Of course, topsoils occur on top of subsoils through which the water from the water-table has to move first. Such a flow system of two or more layers can be 
analysed by superimposing graphs for each layer as will be illustrated with a few examples. Initially the water-table was at $1 \mathrm{~m}$ depth below the top of the potato ridges, but it decreased gradually to $2.7 \mathrm{~m}$ depth (except for the irrigated treatments) in early September.

Critical levels of the water-table for different fluxes can be defined in terms of the associated height of capillary rise assuming a given depth of rooting. Consid-
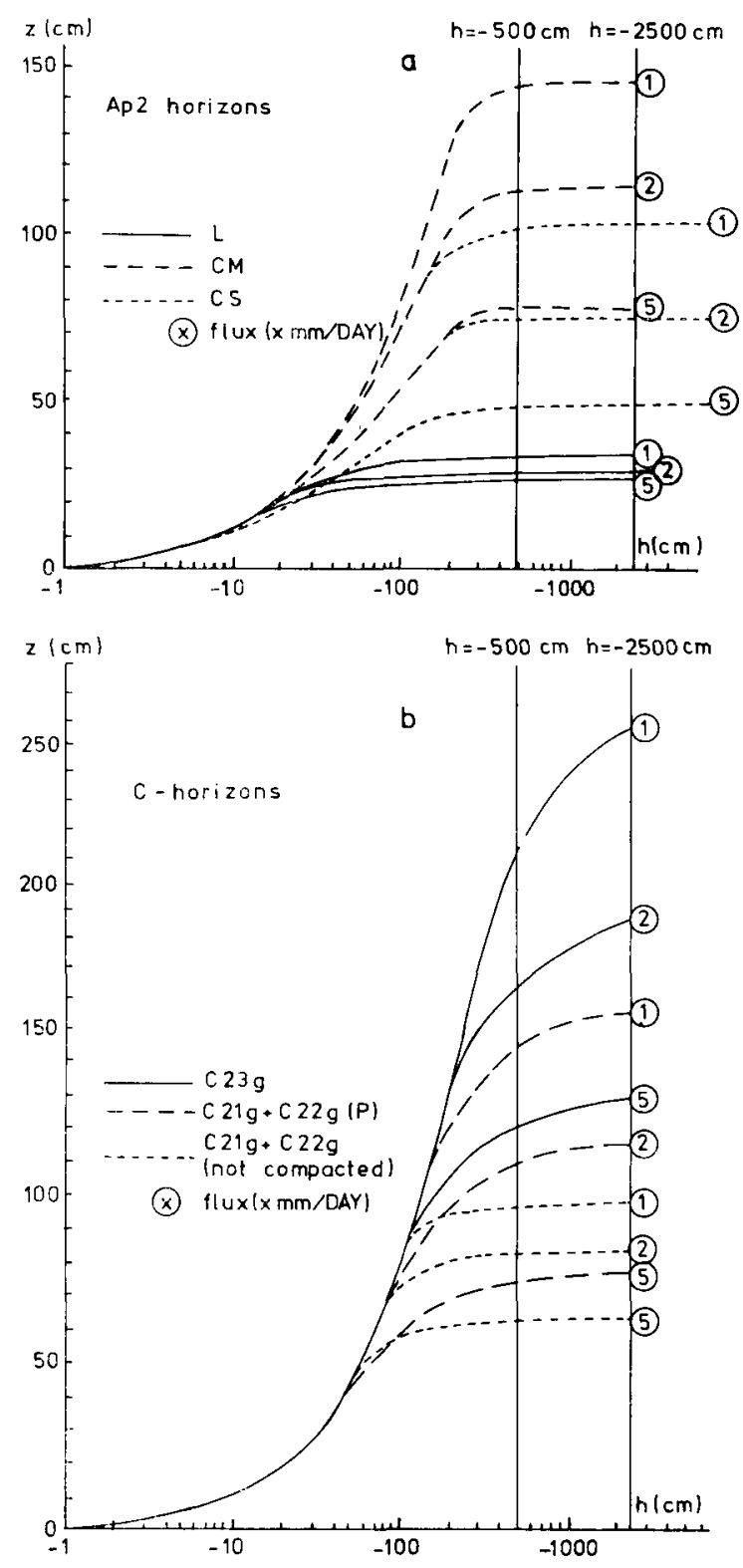

Fig. 8. Theoretical heights (z) of capillary rise calculated for three steady upward fluxes for topsoils (Fig. 8a) and subsoils (Fig. 8b). 


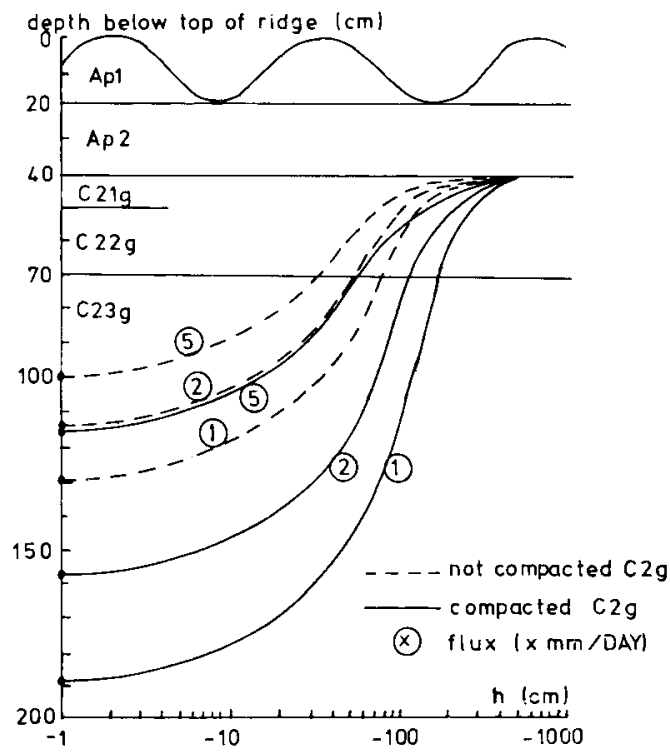

Fig. 9. Critical water levels estimated for three steady upward fluxes to the lower boundary of the Ap2 horizon, which has an assumed steady pressure potential (h) of $-500 \mathrm{~cm}$.

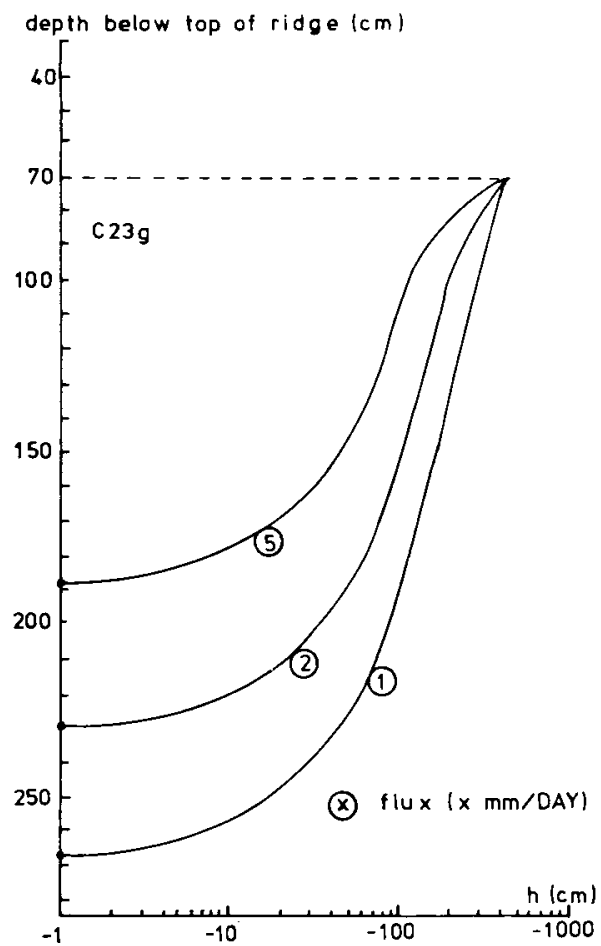

Fig. 10. Critical water levels estimated for three steady upward fluxes to the lower boundary of the C22g horizon, which has an assumed steady pressure potential (h) of $-500 \mathrm{~cm}$. 
ering a two-layer system consisting of the $\mathrm{C} 21 \mathrm{~g}+\mathrm{C} 22 \mathrm{~g}$ and the $\mathrm{C} 23 \mathrm{~g}$, the lowest water level can be defined which still allows upward steady fluxes of, for example, 1,2 and $5 \mathrm{~mm} /$ day at the lower boundary of the $\mathrm{Ap}_{2}$, which is assumed here to have a constant pressure potiential of $-500 \mathrm{~cm}$. Critical water levels were higher for treatment $\mathrm{L}$ than for treatment $\mathrm{P}$ because the capillary rise is higher in the dense ploughpan (Fig. 9).

Deeper water-tables than the critical ones indicated in Fig. 9 result in fluxes lower than $1 \mathrm{~mm} /$ day at the $40 \mathrm{~cm}$ level. Higher fluxes can only be realized when roots grow deeper as they do in all treatments, except $\mathbf{P}$ where roots never reached deeper than $60 \mathrm{~cm}$. This should result in loss of capillary contact and lack of moisture in treatment $\mathbf{P}$ when the water-table is at about $2 \mathrm{~m}$ depth.

As soon as roots reach the level of $70 \mathrm{~cm}$, only the favourable properties of the $\mathrm{C} 23 \mathrm{~g}$ determine capillary rise, which is very high (Fig. 10) assuming a potential of $-500 \mathrm{~cm}$ at $70 \mathrm{~cm}$ depth. Due to deeper root growth in the treatments without the severely compacted subsoil, the earlier picture is reversed and they can now derive more water from capillary rise than treatment $\mathbf{P}$.

The availability of soil hydraulic data, in terms of moisture contents, hydraulic conductivities, moisture retention and water levels allows the approximate calculation of the volume of water uptake by the roots in successive periods during the growing season, as will be shown in a companion paper (van Loon \& Bouma, 1978).

\section{Acknowledgements}

Ing. B. Kroesbergen and Mr A. Boers (Tillage Laboratory, Agricultural University) made soil physical measurements; Mr G. A. van Soesbergen (Soil Survey Institute) determined soil profile characteristics and rooting patterns; $\mathrm{Mr} . \mathrm{H}$. Verlinden (trainee) determined hydraulic conductivity values in the Soil Physics Laboratory of the Soil Survey Institute.

\section{References}

Arya, L. M., D. A. Farrell \& G. R. Blake, 1975. A field study of soil water depletion patterns in presence of growing soybean roots. I. Determination of hydraulic properties of the soil. Proc. Soil Sci. Soc. Am. 39: 424-430.

Bakermans, W. A. P., F. R. Boone \& C. van Ouwerkerk, 1974. New tillage systems: Experiences in Westmaas, 1968-1971. Bedrijfsontwikkeling 5 (7/8): 639-650 (Dutch.)

Bakker, H. de \& J. Schelling, 1966. System of soil classification for the Netherlands. The higher levels. Pudoc, Wageningen, 217 pp. (Dutch, English summary.)

Barley, K. P., 1976. Mechanical resistance of the soil in relation to the growth of roots and emergifg shoots. Agrochimica 20: 173-181.

Boone, F. R., L. A. H. de Smet \& C. D. van Loon, 1975. The influence of compaction in and below the arable layer of a loamy sand on the development of roots, tubers and foliage of potatoes in 1973. Report, 46 pp. (Dutch.)

Bouma, J. \& J. L. Anderson, 1973. Relationships between soil structure characteristics and hydraulic conductivity. In: R. R. Bruce et al. (Ed.), Field soil water regime. Spec. Publ. Soil Sci. Soc. Am. No. 5: 77-105. 
Bouma, J., 1977. Soil survey and the study of water in unsaturated soil. Soil Surv. Pap. No 13. Soil Survey Institute, Wageningen, $107 \mathrm{pp}$.

Feddes, R. A., P. J. Kowalik \& H. Zaradny, 1978. Field water use and crop growth. Series 'Simulation Monographs', Pudoc, Wageningen (in press.)

Kuipers, H., 1968. Bemerkungen zu dem Zusammenhang zwischen Bodendichte und Luft- und Wasserversorgung. In: Proceedings of the International Scientific Symposium 'Problems of soil cultivation' (Brno, Czechoslovakia, 22-24 June 1966).

Letey, J. \& L. H. Stolzy, 1964. Measurement of oxygen diffusion rates with the platinum microelectrode. Hilgardia 35 (20) 545-576.

Loon, C. D. van and J. Bouma, 1978. A case study on the effect of soil compaction on potato growth in a loamy sand soil. 2. Potato plant responses. Neth. J. agric. Sci. 26: 421-429.

Nitzsch, W. von, 1937. Bessere Bodenbearbeitung. R.K.T.L. Schrift No 70. Paul Parey, Berlin, p. $57,88-96$.

Ouwerkerk, C. van \& F. R. Boone, 1970. Soil physical aspects of zero-tillage experiments. Neth. J. agric. Sci. 18: 247-261.

Reymerink, A. 1964. An improved method for studying rooting patterns. Meded. Dir. Tuinb. 27 (1) $42-49$ (Dutoh.)

Soesbergen, G. A. \& Th. C. Vos, 1971. A penetrometer to be applied in soil survey. Interne mededeling No 4, Soil Survey Institute, Wageningen, 10 pp. (Dutch.)

Rijtema, P. E., 1971. A calculation method for estimating agricultural production losses due to groundwater extraction. Nota Inst. Cult. Tech. Waterhuish. No 587 (Dutch).

Soil Survey Staff, 1975. Soil taxonomy. A basic system of soil classification for making and interpreting soil surveys. Soil Conservation Service. USDA-SCS Handbook No 436, 590 pp. 